\title{
Transcatheter Arterial Embolization in Lower Gastrointestinal \\ Bleeding : Ischemia Remains a Concern Even with a Superselective Approach
}

\section{Nykänen, Taina}

2018-08

Nykänen , T , Peltola , E , Kylänpää , L \& Udd , M 2018 , ' Transcatheter Arterial Embolization in Lower Gastrointestinal Bleeding : Ischemia Remains a Concern Even with a Superselective Approach ' , Journal of Gastrointestinal Surgery , vol. 22 , no. 8 , pp. 1394-1403 . https://doi.org/10.1007/s11605-018-3728-7

http://hdl.handle.net/10138/304172

https://doi.org/10.1007/s11605-018-3728-7

publishedVersion

Downloaded from Helda, University of Helsinki institutional repository.

This is an electronic reprint of the original article.

This reprint may differ from the original in pagination and typographic detail.

Please cite the original version. 


\title{
Transcatheter Arterial Embolization in Lower Gastrointestinal Bleeding: Ischemia Remains a Concern Even with a Superselective Approach
}

\author{
Taina Nykänen $^{1}$ (D) $\cdot$ Erno Peltola $^{2} \cdot$ Leena Kylänpää $^{1} \cdot$ Marianne Udd $^{1}$ \\ Received: 15 October 2017 / Accepted: 22 February 2018 / Published online: 16 March 2018 \\ (C) 2018 The Society for Surgery of the Alimentary Tract
}

\begin{abstract}
Purpose To evaluate the safety, efficacy, and feasibility of transcatheter arterial embolization (TAE) in the treatment of lower gastrointestinal bleeding (LGIB).

Methods Study group comprised all patients receiving angiography for LGIB in the Helsinki University Hospital during the period of 2004-2016. Hospital medical records provided the study data. Rebleeding, complication, and mortality rates ( $\leq 30$ days) were the primary outcomes. Secondary outcomes included need for blood transfusions, durations of intensive care unit and hospital admissions, incidence of delayed rebleeding, and long-term complications, as well as overall survival.

Results During the study period, angiography for LGIB was necessary on 123 patients. Out of 123, 55 (45\%) underwent embolization attempts. TAE was technically successful in $53(96 \%)$. Rebleeding occurred in $14(26 \%)$. The complication rate was 36\%, minor complications occurring in $10(19 \%)$ and major in nine (17\%). Major complications resulted in bowel resection in seven $(13 \%)$. Post embolization ischemia was the most common single complication seen in nine (17\%). The mortality rate was $6 \%$. Survival estimates of 1 and 5 years were 79 and $49 \%$.

Discussion LGIB is a severe physiological insult occurring in patients who are often elderly and moribund. Although major post embolization complications occur, transcatheter arterial embolization should be the first-line approach over surgery in profuse LGIB in patients with hemodynamic instability, when colonoscopy fails or is unavailable, or when computerized tomography angiography detects small intestinal bleeding.
\end{abstract}

Keywords Gastrointestinal hemorrhage $\cdot$ Embolization, therapeutic $\cdot$ Angiography

\section{Introduction}

Lower gastrointestinal bleeding (LGIB) refers to intestinal bleeding arising distal to the ligament of Treitz. It is a common cause of hospitalization in surgical emergency units with an incidence of 20-30 per 100,000 and with mortality reaching $5 \% .{ }^{1}$ Accounting for up to $17-40 \%$ of the bleeding episodes, diverticular disease is the most common etiology. Other etiologies include colonic vascular ectasia, colitis,

Taina Nykänen

taina.nykanen@hus.fi

1 Helsinki University Hospital, Abdominal Center and University of Helsinki, Department of Surgery, P.O. BOX 340, FI-00029HUS, Helsinki, Finland

2 Helsinki University Hospital, Helsinki Medical Imaging Center, Helsinki, Finland tumors and post polypectomy bleeding, anorectal causes (e.g., hemorrhoids and varices), and bleeding from the small bowel (e.g., angioectasia, Meckel's diverticula, tumors, Crohn's ileitis). ${ }^{2}$ Of the bleeding episodes, $80 \%$ resolve themselves spontaneously, the remaining requiring interventional management. ${ }^{2}$ As the first-line approach, modern guidelines recommend urgent colonoscopy within $24 \mathrm{~h},{ }^{3,4}$ as it confirms the definitive diagnosis in $74-100 \%{ }^{5}$ and allows simultaneous therapeutic interventions. Colonoscopy requires bowel prep and sedation as well as endoscopy facilities and an experienced endoscopist, which may limit its availability. A readily available method for localizing the bleeding in most emergency rooms is computerized tomography angiography (CTA). It has the ability to visualize bleeding when the bleeding rate exceeds $0.3 \mathrm{ml} /$ min and has a diagnostic yield of 54-79\%. ${ }^{6}$ When CTA is positive for bleeding, another possible therapeutic approach is transcatheter arterial embolization (TAE). It is useful especially in the case of hemodynamic instability, when 
colonoscopy fails, or when the patient would not tolerate bowel cleansing or other invasive procedures. TAE does not come without risks, however. It may have serious sequelae such as bowel ischemia, angiography-related puncture site complications, and contrast-induced kidney failure. ${ }^{6,7}$

The purpose of this study was to evaluate the safety, efficacy, and feasibility of TAE in the treatment of LGIB with rebleeding, complication, and mortality rates ( $\leq 30$ days) as primary outcomes. Secondary outcomes include the need for blood transfusions, the durations of intensive care and hospital admissions, the incidence of delayed rebleeding, and longterm complications, as well as all-cause mortality.

\section{Materials and Methods}

\section{Patients}

The study comprised all patients $\geq 18$ years undergoing angiography and embolization for LGIB in the Helsinki University Hospital during the period 2004-2016. Interventional codes for coeliac, mesenteric, and iliac angiographies and embolizations enabled identifying patients from the hospital picture archiving and communication system (PACS). Clinical, endoscopic, and imaging findings confirmed the diagnosis of LGIB.

\section{Clinical Data and Definitions}

Hospital medical records provided the study data comprising demographic details, comorbidities, medication, symptoms, clinical findings, laboratory and imaging results, interventions, complications, and follow-up notes. Statistics Finland provided the time and cause of death.

Assessing the safety and feasibility of TAE required defining rates for technical success, clinical success, rebleeding, complications, and mortality. When TAE was feasible and post embolization angiography showed discontinuation of bleeding, TAE was technically successful. Clinical success implied no rebleeding, major complications, or mortality within a 30-day follow-up. Rebleeding and delayed rebleeding referred to recurrence of bleeding symptoms within 30 days and more than 30 days from TAE. Reporting complication and mortality rates occurred at 30 days after embolization. The Society of Interventional Radiology Standards of Practice Committee guidelines enabled classifying complications as minor or major. ${ }^{8}$ Minor complications do not necessitate reoperations or result in a significant increase in the level of care. Major complications require therapeutic interventions and may cause a prolonged hospital stay, permanent disability, or death.

\section{Statistical Analysis}

IBM SPSS version 24 (SPSS Inc., Chicago, IL) facilitated statistical analysis. Categorical data is expressed as percentages and continuous data as medians (range). The MannWhitney $U$ test allowed the comparison of continuous data. Univariate binary logistic regression enabled assessing factors associated with recurrent bleeding. Kaplan-Meier analysis gave estimates of survival. Two-tailed tests allowed defining the $P$ values that indicated statistical significance when $<0.05$.

\section{Ethical Approval}

The Helsinki University Hospital Research Board granted the study approval. Finnish law allows conducting medical research using hospital records without patient approval. Thus, obtaining informed patient consent was not necessary.

\section{Initial Evaluation and Management}

The Helsinki University Hospital is a tertiary teaching hospital with a catchment area of 1.6 million people and 24/7 availability for emergency endoscopies and TAE. Referring patients with LGIB occurs from primary health care in the Helsinki area and surrounding hospitals without facilities for emergency interventions for LGIB.

Initial evaluation and management of bleeding patients take place at the surgical emergency room. Patients receive fluid resuscitation and packed red blood cells (RBCs). Other blood products and medications may be necessary to optimize the clotting status and hemodynamics. Resuscitation and stabilization occur at the anesthetist-led intensive monitoring facility of the emergency room, after which admission to the intensive care unit is often unnecessary. Further monitoring of hemodynamically stable patients and arrangements for colonoscopy workup occur at the surgical ward. In case of unstable hemodynamics and continuous bleeding, patients undergo urgent CTA to localize the bleeding. When CTA is positive, referring the patient to angiography and embolization follows. Our institution replaced angiography with CTA in the diagnostics of LGIB in 2007. Until then, angiography also served a diagnostic purpose.

\section{Transcatheter Arterial Embolization}

The detection of the bleeding site occurred with angiography by catheterizing the superior mesenteric artery (SMA) and/or inferior mesenteric artery (IMA) (Fig. 1). If angiography showed no extravasation from these, catheterizing the internal iliac artery followed. Selective angiographs with microcatheter enabled visualizing the exact bleeding arterial branch. When the bleeding site was visible, embolization of the bleeding artery followed as distal as possible; microcoils, gelatine, and 
Fig. 1 An 81-year-old man presented with profuse rectal bleeding. Computerized tomography angiography was positive, showing contrast extravasation and diverticulosis in descending colon (white arrows, top left and right). Immediate angiography took place. Contrast extravasation from the inferior mesenteric artery (black arrow, bottom left) was successfully controlled with coils (black arrow, bottom right). Severe post operative abdominal pain occurred. Two days after embolization sigmoidoscopy showed transmural ischemia in left hemicolon, necessitating left hemicolectomy
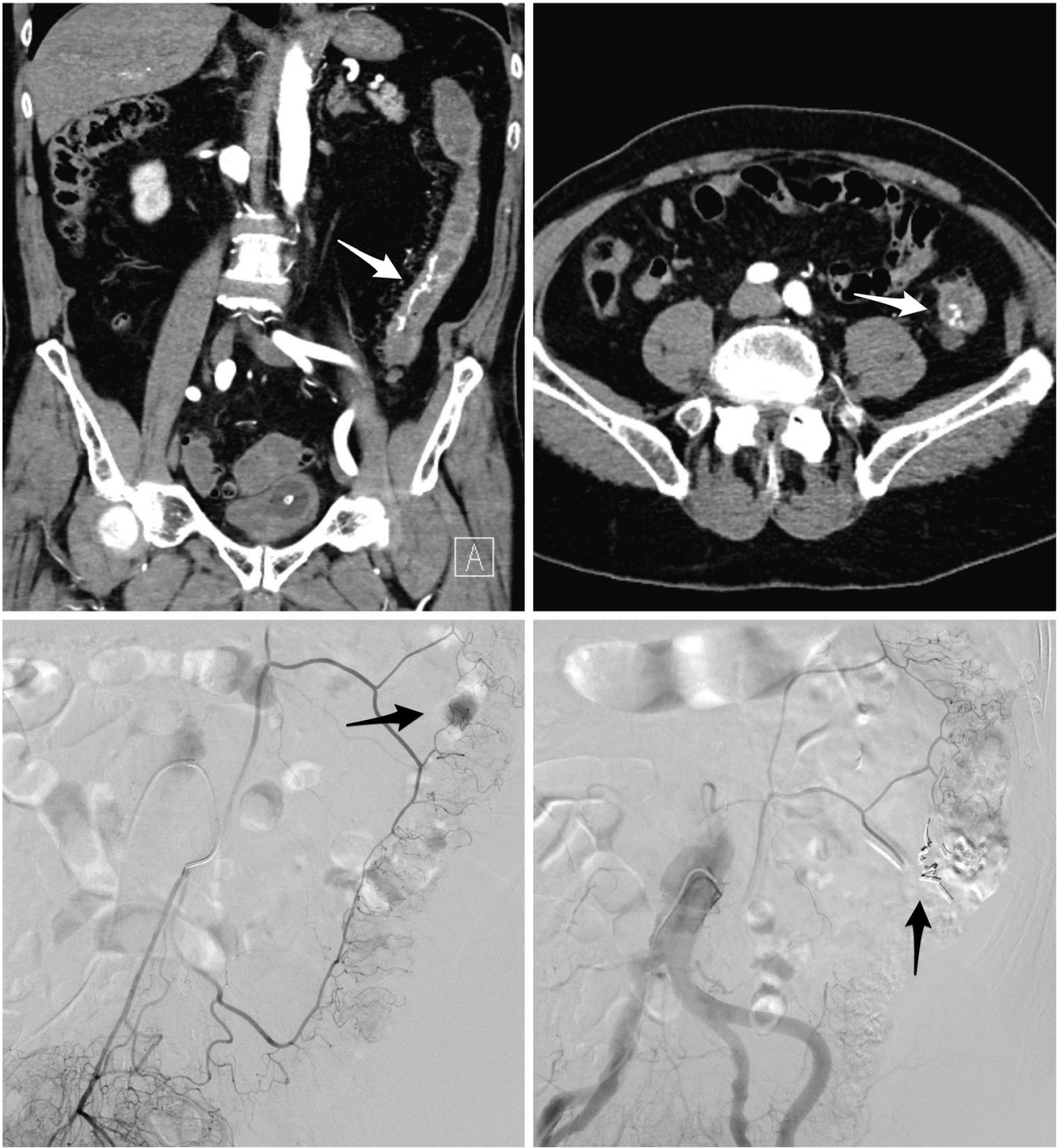

particles being the methods used. Provocation of the bleeding did not occur. When angiography remained negative despite active bleeding in CTA or endoscopy, empirical embolization of the suspected bleeding artery took place in a few complicated cases where laparotomy would have been unfavorable.

\section{Results}

During 2004-2016, LGIB necessitated angiography on 123 patients (Fig. 2). Missing follow-up data lead to the exclusion of two patients. Out of the remaining 121, 71 $(59 \%)$ had negative and $50(41 \%)$ positive angiographies. Out of 121,55 patients -8 with negative and 47 with positive angiographies - underwent an embolization attempt. The procedure was technically successful in $53(96 \%)$ patients, 37 male and 16 female. Table 1 summarizes their baseline characteristics.

\section{Angiography and Embolization Details}

Angiography localized the bleeding in the jejunum or ileum in $12(23 \%)$, caecum or right hemicolon in eight $(15 \%)$, transverse colon in five (10\%), left hemicolon or sigmoid in $14(26 \%)$, and rectum in $14(26 \%)$. The bleeding originated from the branches of SMA and IMA in 47 and $45 \%$ of bleeding events, internal iliac artery explaining the remaining $8 \%$ (Table 2). The median time from hospital admission to angiography and embolization was $9 \mathrm{~h}(0-330)$. Coils were the most common embolization method used, either alone $(62 \%)$ or combined with particles $(11 \%)$ or gelatine (6\%) (Table 2). Periprocedural complications occurred during seven (13\%) embolizations (Table 2). All of these remained clinically irrelevant. After adopting CTA in the diagnostics of LGIB, embolization rate after angiography increased ( 27 vs. $64 \%, P=0.000)$. 


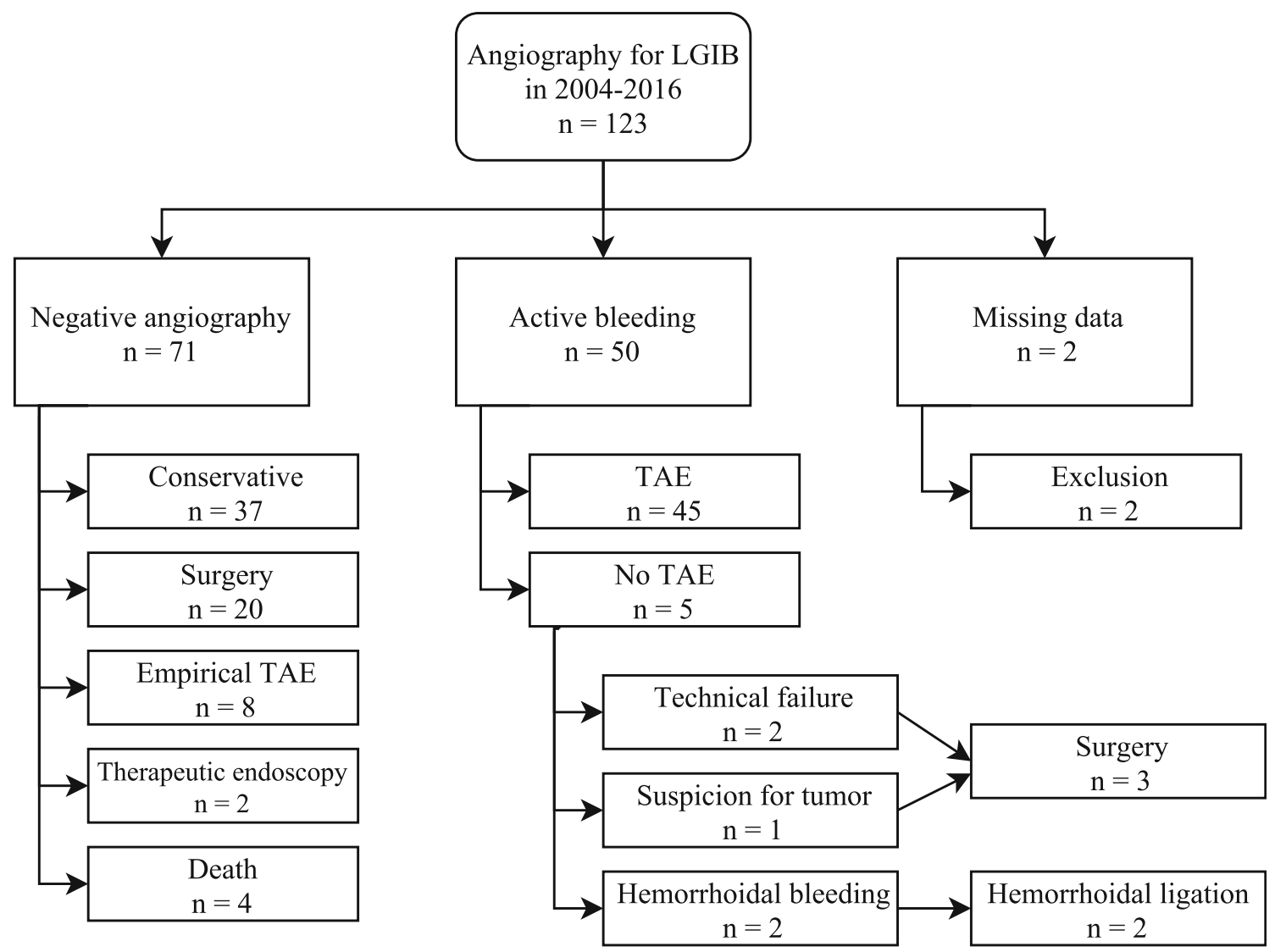

Fig. 2 Flow chart showing the treatment path of the 123 patients undergoing angiography for lower gastrointestinal bleeding (LGIB) in the Helsinki University Hospital during the period 2004-2016. TAE transcatheter arterial embolization

\section{Embolization Success and Failure}

Embolization overall clinical success was $60 \%$. Recurrent bleeding occurred in 14 (26\%), out of which seven (50\%) required reintervention, six (43\%) experienced spontaneous resolution, and one (7\%) died (Fig. 3). The severity of bleeding did not differ between the groups with spontaneous resolution and reintervention (median requirement for units of packed RBCs: 15 (11-58) vs. 18 (6-39), $P=0.486)$. Odds for recurrent bleeding were higher with the increasing amount of red blood cells (RBCs) administered before the salvage $(P=0.032)$ and with bleeding originating from the branches of SMA $(P=0.041)$ (Table 4$)$. The result for SMA was not significant with crosstabulation, however $(P=0.06$, Fisher's exact test). Sex, age, ASA score, anticoagulant therapy, hemoglobin level at presentation, presence of hemodynamic shock or coagulopathy, time to embolization, bleeding site, or underlying etiology were not associated with recurrent bleeding $(P>0.05)$. Rebleeding occurred within a median of 2 days $(0-18)$ of the embolization. Two patients experienced delayed rebleeding: one 88 and the other 204 days after the procedure. After the first bleeding episode, the first patient underwent negative colonoscopy and the second negative gastroscopy and colonoscopy. Further examinations took place for both only after the second bleeding episode. The first received a repeated colonoscopy and polypectomy for rectal polyp that was most likely missed during the first endoscopy. The second underwent magnetic resonance enterography (MRE) showing an intestinal tumor. Ileal resection followed with the diagnosis of a malignant gastrointestinal stromal tumor (GIST).

\section{Complications}

Complication rate ( $\leq 30$ days) was $36 \% ; 19$ patients experiencing post embolization problems (Table 3). Major complications occurred in nine (17\%). Surgery was necessary during the same hospital admission on six - due to ischemia in five $(9 \%)$ and for a suspected catheter-induced mechanical bowel perforation in one (2\%) (pathology report showed intramural hematoma and perforation but no ischemia close to the coils). Non-surgical management was initially sufficient in two: One patient with radiation proctitis received endoscopic argon coagulation for recurrent bleeding after TAE. Post embolization ischemic colitis, sepsis, and endocarditis developed, necessitating medical treatment. The other recovered from ischemic colitis but required surgery for iatrogenic colon perforation after a balloon dilatation of the ischemic stricture 2 months later. One patient with end-stage endometrial cancer 
Table 1 Patient baseline characteristics

\begin{tabular}{|c|c|}
\hline & $n=53$ \\
\hline Age $^{\mathrm{a}}$, (years) & $72(30-95)$ \\
\hline \multicolumn{2}{|l|}{ Sex, $n(\%)$} \\
\hline Male/female & $37(70) / 16(30)$ \\
\hline \multicolumn{2}{|l|}{ ASA grade, $n(\%)$} \\
\hline 1 & $3(6)$ \\
\hline 2 & $9(17)$ \\
\hline 3 & $29(54)$ \\
\hline 4 & $10(19)$ \\
\hline 5 & $2(4)$ \\
\hline \multicolumn{2}{|l|}{ Risk factors, $n(\%)$} \\
\hline Anticoagulant therapy & $32(60)$ \\
\hline NSAID & $1(2)$ \\
\hline \multicolumn{2}{|l|}{ Symptoms, $n(\%)$} \\
\hline Hematemesis & $0(0)$ \\
\hline Hematochezia & $49(93)$ \\
\hline Melena & $12(23)$ \\
\hline Abdominal pain & $6(11)$ \\
\hline \multicolumn{2}{|l|}{ Bleeding onset, $n(\%)$} \\
\hline Home/health-care facility & $43(81) / 10(19)$ \\
\hline \multicolumn{2}{|l|}{ Clinical findings on admission } \\
\hline Systolic blood pressure $^{\mathrm{a}},(\mathrm{mmHg})$ & $111(66-178)$ \\
\hline Heart rate, $(\mathrm{BPM})$ & $82(40-124)$ \\
\hline Unstable hemodynamics ${ }^{\mathrm{b}}, n(\%)$ & $24(45)$ \\
\hline Noradrenaline infusion, $n(\%)$ & $15(27)$ \\
\hline Hemoglobin $^{\mathrm{a}}(\mathrm{g} / \mathrm{l})$ & $84(33-147)$ \\
\hline Platelet count $^{\mathrm{a}}(\mathrm{E} 9 / \mathrm{l})$ & $179(59-473)$ \\
\hline Thromboplastin time ${ }^{\mathrm{a}}(\mathrm{TT} \%)$ & $63(1-121)$ \\
\hline Coagulopathy $^{\mathrm{c}}, n(\%)$ & $16(30)$ \\
\hline \multicolumn{2}{|l|}{ Pre-embolization investigations, $n(\%)$} \\
\hline Gastroscopy & $19(36)$ \\
\hline Colonoscopy or sigmoidoscopy & $10(19)$ \\
\hline CTA & $34(64)$ \\
\hline Positive/negative & $30 / 4$ \\
\hline
\end{tabular}

ASA American Society of Anesthesiology, NSAID non-steroidal anti-inflammatory drug, $B P M$ beats per minute, $T T$ thromboplastin time, $C T A$ computerized tomography angiography

${ }^{a}$ Median (range)

${ }^{\mathrm{b}}$ Systolic blood pressure $<100 \mathrm{mmHg}$ and/or heart rate $>100$ beats per minute

${ }^{\mathrm{c}}$ Thrombocyte count $<50$ E9/L and/or TT\% $<50$

died of post embolization rectal ischemia. Minor complications occurred in 10 (19\%) and comprised self-limiting ischemia, pneumonia, puncture site hematoma, and post embolization abdominal pain. They did not require further interventions. The most prevalent single complication was computerized tomography- or endoscopy-verified ischemia occurring in nine $(17 \%)$. Surgery was necessary on six, two recovered spontaneously without any permanent sequelae, and one died.
Table 2 Angiography and embolization details

\begin{tabular}{ll}
\hline & $n=53$ \\
Indication for embolization, $n(\%)$ & \\
Active bleeding & $45(85)$ \\
Empirical & $8(15)$ \\
Time to embolization $^{\text {a }}(\mathrm{h})$ & $9(0-330)$ \\
Culprit vessel, $n(\%)$ & \\
SMA & $25(47)$ \\
Jejunal/ileal branches & 12 \\
Ileocolic artery & 4 \\
Right colic artery & 4 \\
Medial colic artery & 4 \\
Lienal flexure branches & 1 \\
IMA & $24(45)$ \\
Left colic artery & 13 \\
Sigmoid arteries & 2 \\
Superior rectal artery & 9 \\
Internal iliac artery & 9 \\
Embolization method, $n(\%)$ & $4(8)$ \\
Coils & \\
Gelatine & $33(62)$ \\
Particles & $8(15)$ \\
Coils and particles & $1(2)$ \\
Coils and gelatine & $6(11)$ \\
Particles and gelatine & $3(6)$ \\
Perioperative complications, $n(\%)$ & $2(4)$ \\
Coil misplacement & $7(13)$ \\
Dissection & 3 \\
Perforation & 1 \\
Perioperative ischemic pain & 1 \\
\hline & 2 \\
\hline
\end{tabular}

SMA superior mesenteric artery, IMA inferior mesenteric artery

${ }^{\mathrm{a}}$ Median (range)

Crosstabulation or univariate logistic regression did not reveal any associations between the incidence of ischemia and the bleeding site or the embolized artery $(P<005)$. Contrastinduced acute kidney insufficiency did not occur.

\section{Mortality}

The mortality rate ( $\leq 30$ days) was $6 \%$; three patients dying within 30 days of TAE (Table 4). One patient who suffered a warfarin overdose (INR $>9$ ) died of profuse bleeding from the transverse colon. One died of exacerbation of underlying medical conditions after controlling of the bleeding. The patient with end-stage endometrial cancer died of post embolization ischemia. After excluding the three patients dying within 30 days of the embolization, the median duration of the follow-up was 31 months (3-174). By the time of data retrieval, 26 (49\%) patients had died; neurological disorders (27\%), malignancies (19\%), and cardiovascular diseases (15\%) being 


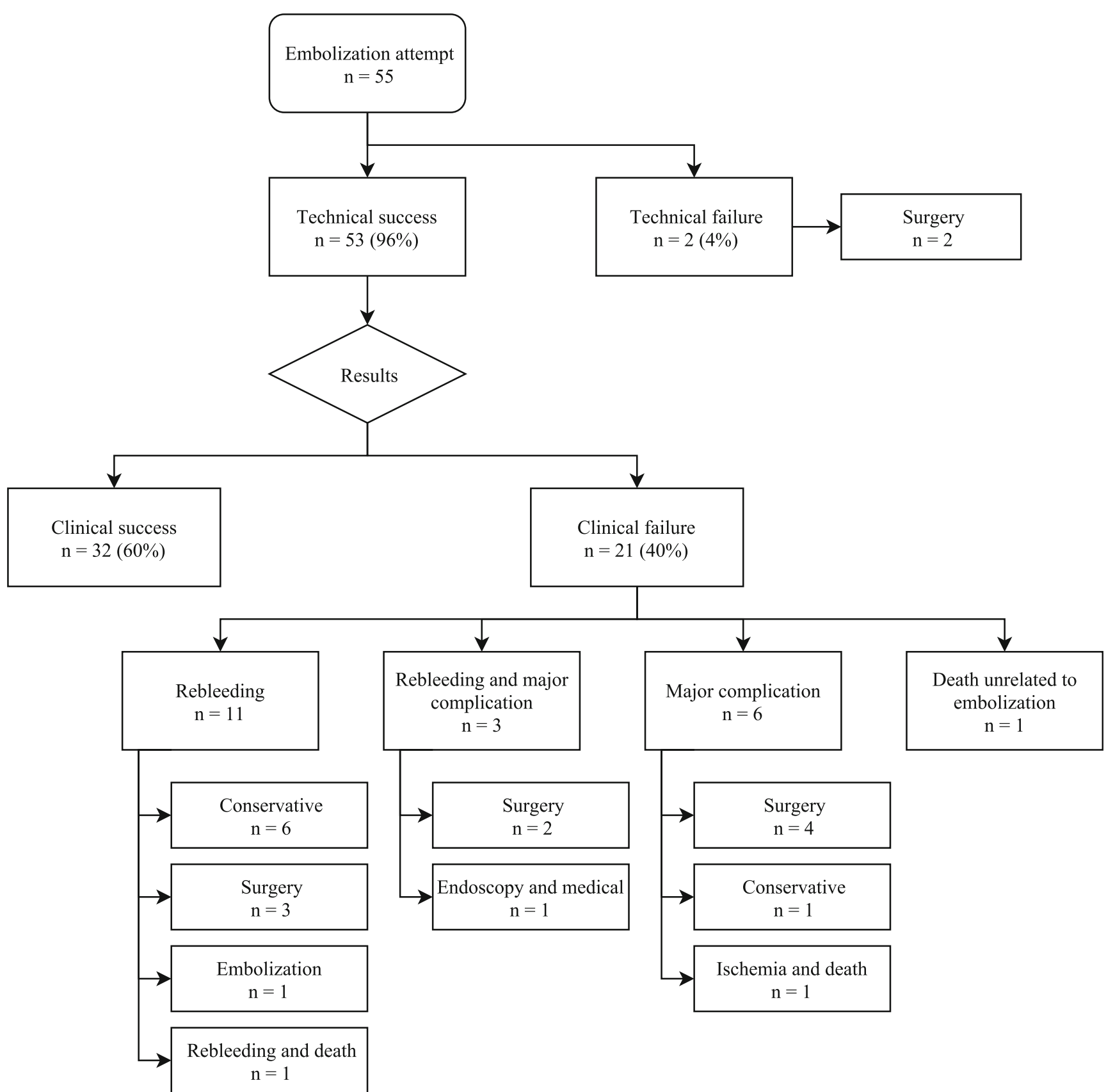

Fig. 3 Flow chart showing the results $(\leq 30$ days $)$ of transcatheter arterial embolization (TAE) in the study group of 55 patients undergoing embolization attempt for lower gastrointestinal bleeding (LGIB) in the Helsinki University Hospital during 2004-2016. Technical success: immediate cessation of bleeding after TAE, clinical success: no

the most common causes of death. Survival estimates of 1 and 5 years were $79 \%$ (asymptotic 95\% CI 67.7-90.5) and 49\% (asymptotic 95\% CI 32.8-64.6).

\section{Empirical Embolization}

Out of 53, 8 underwent empirical embolization after negative angiography. A positive CTA beforehand guided the rebleeding, major complications or mortality within 30 days of TAE, rebleeding: recurrence of bleeding symptoms within 30 days of TAE, major complication: complication that requires therapeutic intervention and may result in prolonged hospital stay, permanent disability, or death

embolization in five and metallic clips inserted during endoscopy in one. With the last two, the indication for empirical embolization was clinically diagnosed as bleeding from a rectal tumor: the first had newly diagnosed rectal carcinoma with definitive surgical treatment planned after neoadjuvant chemoradiation, and the other had inoperable metastatic rectal cancer with a rectovesical fistula. After empirical TAE, recurrent bleeding occurred in three $(38 \%)$, resolving 
Table 3 Results

\begin{tabular}{lc}
\hline & $n=53$ \\
Recurrent bleeding, $n(\%)$ & $14(26)$ \\
Mortality rate, $n(\%)$ & $3(6)$ \\
Complication rate, $n(\%)$ & $19(36)$ \\
Minor, $n(\%)$ & $10(19)$ \\
Major, $n$ (\%) & $9(17)$ \\
Need for blood transfusions (units of RBCs) ${ }^{\mathrm{a}}$ & $12(2-58)$ \\
$\leq 10$ units of RBCs, $n(\%)$ & $23(43)$ \\
11-20 units of RBCs, $n(\%)$ & $20(38)$ \\
$>20$ units of RBCs, $n(\%)$ & $6(11)$ \\
Missing data & $4(8)$ \\
Duration of ICU treatment, (day) ${ }^{\mathrm{a}}$ & $0(0-6)$ \\
Duration of hospital admission, $(\text { day })^{\mathrm{a}}$ & $7(1-91)$ \\
$\leq 7$ days, $n(\%)$ & $27(51)$ \\
8-14 days, $n(\%)$ & $13(25)$ \\
14-21 days, $n(\%)$ & $9(17)$ \\
$>21$ days, $n(\%)$ & $4(7)$ \\
Follow-up data $>30$ days & \\
Delayed rebleeding, $n(\%)$ & $2(4)$ \\
Ischemic strictures, $n(\%)$ & $1(2)$ \\
Duration of follow-up, (months) ${ }^{\mathrm{a}}$ & $31(3-174)^{\mathrm{b}}$ \\
Etiology of bleeding, $n(\%)$ & \\
Diverticular disease & $21(39)$ \\
Malignant tumor & $6(11)$ \\
Post polypectomy & $7(13)$ \\
Colitis & $4(8)$ \\
Radiation proctitis & $2(4)$ \\
Angioectasia & $1(2)$ \\
GVHD & $1(2)$ \\
Benign tumor & $19)$ \\
\hline No definitive diagnosis & \\
\hline
\end{tabular}

$R B C$ red blood cell, $I C U$ intensive care unit, GVHD graft versus host disease

${ }^{\mathrm{a}}$ Median (range)

${ }^{\mathrm{b}}$ Three patients dying $\leq 30$ days after embolization excluded

spontaneously in all of them. The incidence of recurrent bleeding was not significantly higher after empirical embolization than after embolization for active bleeding $(P=0.422)$. Major complications occurred in $2(25 \%)$, both leading to bowel resection. Patients with empirical embolization received a median of 13 (4-27) units of packed RBCs.

\section{Etiology of Bleeding}

The most prevalent etiology of LGIB was diverticular disease, accounting for $39 \%$ of the bleeding episodes (Table 3). Hemodynamic instability often resulted in embolization without preceding diagnostic workup for the etiology of bleeding. Additional examinations took place at outpatient clinics after
Table 4 Univariate logistic regression modeling for predictors of recurrent bleeding

\begin{tabular}{|c|c|c|c|}
\hline & OR & $95 \% \mathrm{CI}$ & $P^{\mathrm{d}}$ \\
\hline $\operatorname{Sex}(m / f)$ & 3.36 & $0.66-17.21$ & 0.146 \\
\hline Age ( $>70$ years $/<70$ years $)$ & 0.86 & $0.25-2.91$ & 0.805 \\
\hline \multicolumn{4}{|l|}{ ASA score ${ }^{\mathrm{a}}$} \\
\hline ASA3/ASA $1+2$ & 5.79 & $0.65-51.51$ & 0.115 \\
\hline $\mathrm{ASA} 4+5 / \mathrm{ASA} 1+2$ & 3.67 & $0.32-41.59$ & 0.294 \\
\hline Anticoagulant therapy (year $/ n$ ) & 1.93 & $0.52-7.24$ & 0.329 \\
\hline Hemodynamic shock $^{\mathrm{b}}$ (year/n) & 0.59 & $0.17-2.06$ & 0.404 \\
\hline Coagulopathy ${ }^{\mathrm{c}}$ (year/n) & 1.41 & $0.39-5.17$ & 0.600 \\
\hline $\mathrm{Hb}(<80 \mathrm{~g} / \mathrm{l} />80 \mathrm{~g} / \mathrm{l})$ & 1.44 & $0.42-4.90$ & 0.562 \\
\hline Units of RBCs before salvage & 1.12 & $1.01-1.24$ & 0.032 \\
\hline Time to embolization ${ }^{\mathrm{d}}(\mathrm{h})$ & 0.99 & $0.99-1.01$ & 0.532 \\
\hline Etiology of bleeding & & & NS \\
\hline Bleeding site & & & NS \\
\hline Culprit vessel SMA & 4.00 & $1.06-15.08$ & 0.041 \\
\hline
\end{tabular}

ASA American Society of Anesthesiology, $R B C$ red blood cell, SMA superior mesenteric artery, $N S$ non-significant

${ }^{a}$ ASA 1 combined with 2 and ASA4 combined with 5 due to small number of patients

${ }^{\mathrm{b}}$ Systolic blood pressure $<100 \mathrm{mmHg}$ and/or heart rate $>100$ beats per minute

${ }^{\mathrm{c}}$ Thrombocyte count $<50$ E9/L and/or thromboplastin time $<50$ (TT\%)

${ }^{\mathrm{d}}$ Time from hospital admission to embolization (h)

${ }^{\mathrm{e}}$ Univariate binary logistic regression, significant at $P<0.05$

the initial hospital admission with a median delay of 9 weeks (1-38). Confirming the etiology occurred with pre or post embolization colonoscopy in 32 (60\%), capsule endoscopy in five (9\%), and double-balloon enteroscopy (DBE) in one (2\%). CT colonography and MRE were useful in one (2\%). Surgical bowel resection was sufficient in seven (13\%). Out of 53, $11(21 \%)$ did not undergo further diagnostics: CTA findings were convincing enough in five, three were of advanced age, and three died within 30 days of TAE. No definitive diagnosis could be established in 10 (19\%), although five of these received endoscopic examinations after TAE (colonoscopy, capsule endoscopy) (Table 3). The remaining five only underwent pre-embolization CTA or angiography but no endoscopic examinations (two for reasons not clear, two died within 30 days of TAE, and one was of advanced age).

\section{Discussion}

The current study shows a rebleeding rate ( $\leq 30$ days) of $26 \%$ and mortality rate ( $\leq 30$ days) of $6 \%$. The findings are consistent with recently published studies reporting rebleeding rates of $7.7-26 \%$ and mortality rates of $0-31.5 \%$ (Table 5). ${ }^{9-18}$

Ischemic complications were prevalent; the aforementioned studies report ischemia in $3-13 \%$ while in the 
Table 5 Summary of current results and other recent studies reporting the safety and efficacy of TAE in the treatment of lower gastrointestinal bleeding

\begin{tabular}{|c|c|c|c|c|c|c|c|c|}
\hline Author & $\begin{array}{l}\text { Recruitment } \\
\text { period }\end{array}$ & Number & $\begin{array}{l}\text { Technical } \\
\text { success }^{1} \\
(\%)\end{array}$ & $\begin{array}{l}\text { Recurrent } \\
\text { bleeding }^{2} \\
(\%)\end{array}$ & $\begin{array}{l}\text { Ischemia }^{3} \\
(\%)\end{array}$ & $\begin{array}{l}\text { Mortality } \\
(\%)\end{array}$ & $\begin{array}{l}\text { Survival } \\
1 \text { year }(\%)\end{array}$ & $\begin{array}{l}\text { Survival } \\
5 \text { years }(\%)\end{array}$ \\
\hline Nykänen et al. 2018 & 2004-2016 & 53 & 96 & 26 & 17 & 6 & 79 & 49 \\
\hline Bua-ngam et al. 2017 & $2007-2015$ & 39 & 92 & 26 & 13 & $31.5^{\mathrm{b}}$ & & \\
\hline Hur et al. 2014 & 2006-2013 & 112 & 96.4 & 17.4 & 4.6 & $25^{\mathrm{b}}$ & & \\
\hline Teng et al. 2013 & 1997-2009 & 26 & 84.6 & 7.7 & $7.7^{\mathrm{a}}$ & 19.2 & 58.2 & 43.1 \\
\hline Huang et al. 2011 & 2006-2008 & 27 & 100 & 14.8 & 0 & 44 & & \\
\hline Gillespie et al. 2010 & 1998-2008 & 38 & 93 & 24 & 0 & 2.6 & & \\
\hline Maleux et al. 2009 & $1997-2008$ & 39 & 100 & 15 & $10^{\mathrm{a}}$ & 15 & 70.6 & 50.8 \\
\hline Frodsham et al. 2009 & 2005-2009 & 14 & 100 & 14 & 0 & 7 & & \\
\hline Koh et al. 2009 & $2000-2006$ & 68 & 100 & 8.8 & 5.9 & 0 & & \\
\hline Tan et al. 2008 & $2000-2007$ & 32 & 97 & 22 & $3^{\mathrm{a}}$ & 9 & & \\
\hline Lipof et al. 2008 & 1999-2005 & 75 & 97 & 16 & 7 & 11 & & \\
\hline
\end{tabular}

$T A E$ transcatheter arterial embolization

${ }^{1}$ Immediate cessation of bleeding after TAE

${ }^{2}$ Bleeding recurrence within 30 days of TAE

${ }^{3}$ Ischemic complications within 30 days of TAE

${ }^{4}$ Mortality within 30 days of TAE

${ }^{a}$ Ischemic complications requiring bowel resection

${ }^{\mathrm{b}}$ In-hospital mortality after TAE

present study it occurred in $17 \%$ and necessitated surgery in $11 \%$. The actual incidence of ischemia could be even higher, as 5 (9\%) patients experienced spontaneously resolving post embolization abdominal pain but did not undergo any endoscopic or CT examinations. In current study, the patients suffering surgery-requiring or lethal ischemia may have received embolization less selectively than what is optimal. Superselective embolization should cover only the extravasating vasa recta artery or arteries. A retrospective review of the angiograms of patients with ischemia shows parallel coils in two or three vasa recta vessels and additional coils even in the level of the marginal artery in two patients. The findings emphasize the importance of as superselective approach as possible to minimize the risk of ischemia.

CTA directs clinical decision-making between colonoscopy, TAE, and surgery, and is the diagnostic method of choice for patients with active LGIB and hemodynamic instability. Colonoscopy has a diagnostic yield of 74 to $100 \%$ and the potential to eliminate embolization-related risks. It is the recommended first-line intervention in the diagnosis and management of LGIB for hemodynamically stable patients. Colonoscopy seems a rational approach also in post operative bleeding from the colon. Anastomotic bleeding or post polypectomy bleeding should not be difficult to locate. Moreover, colonoscopy does not compromise circulation in the area of anastomosis or thin polypectomy sites. Colonoscopy after proper bowel cleansing should be the first-line intervention for all hemodynamically stable patients with LGIB unless the preceding CTA detects bleeding in the small intestine. The number of urgent colonoscopies $(\leq 24 \mathrm{~h})$ in our institution has been low mostly due to the limited availability of endoscopic services outside regular working hours. It is noteworthy that despite current treatment algorithms for LGIB, only $19 \%$ of patients received colonoscopy and 36\% gastroscopy before embolization in the current study. Angiography localized the bleeding in the rectum in $26 \%$ and at least these, as most of the patients embolized for post polypectomy bleeding, should have rather been diagnosed and managed with endoscopy instead of predisposing the patients to the risks of angiography and embolization.

Bleeding in the small intestine comprises less than $15 \%$ of all LGIB. ${ }^{1,6}$ In the selected population of the present study, however, small intestinal sources explained the bleeding in $23 \%$. In their similar cohort of patients, Gillespie et al. reported bleeding from the small intestine in $34 \% .{ }^{13}$ With this in mind, surgeons dealing with profuse LGIB should avoid performing blind subtotal colectomies and invest every effort in localizing the bleeding. A reasonable first-line approach in small intestinal bleeding is angiography and embolization. Coil embolization should be the preferred method, as the palpable coils can guide surgical resection if bleeding recurs. Coils are also easier to position and control than particles with 
a smaller risk for non-target embolization and consequent ischemia. After controlling the bleeding, further diagnostics for the underlying etiology with capsule endoscopy or MRE are of great importance. In the present study, a small intestinal tumor was detectable in four out of $12(33 \%)$ patients bleeding from the small bowel. The pathology report showed GIST in two and a neuroendocrine tumor in one. Polypectomy for Peutz-Jeghers polyposis resulted in bleeding after DBE in the remaining one.

Previous studies on the safety and efficacy of TAE include patients embolized after positive angiography. Intermittent bleeding may render angiography negative even after positive CTA. Due to the risk of post embolization ischemia, empirical embolization for LGIB after a negative angiogram is generally discouraged, and thus not a routine practice. The validity of this paradigm in the era of CTA and evolving imaging techniques is increasingly questioned, however. Gupton described a case of successful empirical embolization, where the preceding positive CTA guided the superselective embolization of the right inferior rectal artery. ${ }^{19}$ The current study included eight empirically embolized patients with rebleeding, complication (major complications), and mortality rates of 38, 25, and $0 \%$, respectively. Rather than being routine practice, most of these patients received empirical embolization as the last resort in complicated situations where clinicians wanted to avoid laparotomy. Embolization occurred after visualizing the bleeding artery in CTA or endoscopy. In our experience, however, embolizing the true culprit artery in negative angiography according to a positive CTA is uncertain and difficult. Adding the considerable risk of post embolization ischemia, we do not recommend empirical embolizations in LGIB with current imaging methods and embolization techniques.

The study is limited due to its single-center setting, retrospective nature, and small study population that may render true statistical associations undetected. The strength of the study lies in its long follow-up, enabling assessing the patency of the bleeding control after embolization, incidence of ischemic bowel strictures, and long-term survival.

As a conclusion, TAE has a well-established role in the treatment of LGIB. Services from interventional radiologists should be available in hospitals attending for abdominal emergencies. Embolization benefits only a small proportion of patients with LGIB, however. The majority of the bleeding episodes resolve themselves spontaneously. Even during the era of routine preceding CTA, the current study proved embolization feasible after angiography in only $64 \%$. Although major post embolization complications were prevalent, LGIB per se is a severe physiological insult occurring in patients who are often elderly and moribund. Transcatheter arterial embolization should be the first-line approach over surgery in profuse LGIB for patients with hemodynamic instability, when colonoscopy fails or is unavailable, or when computerized tomography angiography detects bleeding in the small intestine. All other patients should undergo urgent colonoscopy after proper bowel cleansing. To avoid predisposing patients with LGIB to unnecessary complications in TAE or surgery, emergency endoscopic services should be of high quality and available at short notice.

Acknowledgements The authors would like to thank statistician Harri Mustonen for his valuable advice and comments.

Grant Support Helsinki University Hospital Research Fund

Pehr Oscar Klingendahl's Fund

Waldemar von Frenckell's Foundation

Finnish-Norwegian Medical Foundation

Author Contribution Taina Nykänen (TN), Marianne Udd (MU) and Leena Kylänpää (LK) designed the study. Erno Peltola (EP) identified patients from the hospital registry. TN performed data collection and analysis. TN and EP drafted the manuscript while MU and LK provided supervision. All authors have critically commented the manuscript and approved the final version.

\section{References}

1. Strate LL. Lower GI Bleeding: Epidemiology and diagnosis. Gastroenterology Clinics of North America. 2005;34(4):643-64.

2. Zuccaro G. Epidemiology of lower gastrointestinal bleeding. Best Pract Res Clin Gastroenterol. 2008;22(2):225-32.

3. Strate LL, Gralnek IM. ACG clinical guideline: Management of patients with acute lower gastrointestinal bleeding. Am J Gastroenterol. 2016;111(4):459-74.

4. Pasha SF, Shergill A, Acosta RD, Chandrasekhara V, Chathadi KV, Early D, et al. The role of endoscopy in the patient with lower GI bleeding. Gastrointest Endosc. 2014;79(6):875-85.

5. Lhewa DY. Pros and cons of colonoscopy in management of acute lower gastrointestinal bleeding. World J Gastroenterol. 2012;18(11):1185-6.

6. Marion Y, Lebreton G, Le Pennec V, Hourna E, Viennot S, Alves A. The management of lower gastrointestinal bleeding. J Visc Surg. 2014;151(3):191-201.

7. Walker TG. Angiographic evaluation and management of acute gastrointestinal hemorrhage. World J Gastroenterol. 2012;18(11): 1191-11.

8. Angle JF, Siddiqi NH, Wallace MJ, Kundu S, Stokes LA, Wojak JC, et al. Quality improvement guidelines for percutaneous transcatheter embolization. J Vasc Interv Radiol. 2010;21(10):1479-86.

9. Bua-ngam C, Norasetsingh J, Treesit T, Wedsart B, Chansanti O, Tapaneeyakorn J, et al. Efficacy of emergency transarterial embolization in acute lower gastrointestinal bleeding: A single-center experience. Diagn Interv Imaging. 2017;98(6):499-505.

10. Hur S, Jae HJ, Lee M, Kim H-C, Chung JW. Safety and efficacy of transcatheter arterial embolization for lower gastrointestinal bleeding-A single-center experience with 112 patients. J Vasc Interv Radiol. 2014;25(1):10-9.

11. Teng H-C, Liang H-L, Lin Y-H, Huang J-S, Chen C-Y, Lee S-C, et al. The Efficacy and long-term outcome of microcoil embolotherapy for acute lower gastrointestinal bleeding. Korean J Radiol. 2013;14(2):259-10.

12. Huang CC, Lee CW, Hsiao JK, Leung PC, Liu KL, Tsang YM, et al. N-butyl cyanoacrylate embolization as the primary treatment 
of acute hemodynamically unstable lower gastrointestinal hemorrhage. J Vasc Interv Radiol. 2011;22(11):1594-9.

13. Gillespie CJ, Sutherland AD, Mossop PJ, Woods RJ, Keck JO, Heriot AG. Mesenteric embolization for lower gastrointestinal bleeding. Dis Colon Rectum. 2010;53(9):1258-64.

14. Maleux G, Roeflaer F, Heye S, Vandersmissen J, Vliegen A-S, Demedts I, et al. Long-term outcome of transcatheter embolotherapy for acute lower gastrointestinal hemorrhage. Am J Gastroenterol. 2009;104(8):2042-6.

15. Koh DC, Luchtefeld MA, Kim DG, Knox MF, Fedeson BC, VanErp JS, et al. Efficacy of transarterial embolization as definitive treatment in lower gastrointestinal bleeding. Colorectal Dis. 2009;11(1):53-9.
16. Tan K-K, Wong D, Sim R. Superselective embolization for lower gastrointestinal hemorrhage: An institutional review over 7 years. World J Surg. 2008;32(12):2707-15.

17. Lipof T, Sardella WV, Bartus CM, Johnson KH, Vignati PV, Cohen JL. The efficacy and durability of super-selective embolization in the treatment of lower gastrointestinal bleeding. Dis Colon Rectum. 2008;51(3):301-5.

18. Frodsham A, Berkmen T, Ananian C, Fung A. Initial experience using n-butyl cyanoacrylate for embolization of lower gastrointestinal hemorrhage. J Vasc Interv Radiol. 2009;20(10):1312-9.

19. Gupton T, Cura M. The case for computed tomographic angiography for initial management of lower gastrointestinal hemorrhage. Baylor University Medical Center Proceedings. 2017;30(3):353-4. 